DOI: $10.4274 /$ tpa.46.62

\title{
Bir devlet hastanesinde çok düşük doğum ağırlıklı yenidoğanlarda hastalık ve ölüm oranları
}

\section{The ratio of mortality and morbidity in very low birth weight infants in a public hospital}

\author{
Yekta Canbak, İbrahim Şilfeler, Bayram Ali Dorum, Hilal Kurnaz, Sevil Dorum* \\ S.B. Okmeydanı Eğitim ve Araştırma Hastanesi Çocuk Kliniği, İstanbul, Türkiye \\ *S.B. Zeynep Kamil Kadın Doğum ve Çocuk Hastalıkları Hastanesi, Çocuk Kliniği, istanbul, Türkiye
}

\section{Özet}

Amaç: Hastanemiz yenidoğan yoğun bakım birimindeki çok düşük doğum ağılıklı hastaların hastalık ve ölüm oranlarını belirlemek amacıyla hastalar geriye dönük olarak incelendi.

Gereç ve Yöntem: Hastanemiz yenidoğan yoğun bakım biriminde iki yıl içerisinde yatarak tedavi alan çok düşük doğum ağırlıklı erken doğmuş bebekler arasında çalıșma ölçütlerine uyan 94 olgu çalışmaya alındı. Bu olguların verileri (gebelik yaşı, doğum tartısı, perinatal risk etmenleri, hastanede yatış süreleri, sürfaktan tedavisi, mekanik ventilasyon uygulamaları, sıkıntılı solunum sendromu (SSS), ventriküler içi kanama, periventriküler lökomalasi, nekrotizan enterokolit, kronik akciğer hastalığı ve prematüre retinopatisi) kaydedilip istatistiksel incelemeleri yapıldı.

Bulgular: Çalışmamızda çok düşük doğum ağırlıklı bebeklerde ölüm oranı \%25,5 olarak bulundu. En sık karşılaşılan anneye ait risk etkenleri preeklampsi/eklampsi $(\% 26,3)$ olup sonuçlarımız "NICHD Neonatal Network" grubunun verileri ile uyumluydu. Çalışmamızda grup1'de SSS oranı \%100, grup 2'de \%93,8, grup 3'te \%78,3 ve grup 4'te ise \%47,6 olup SSS (+) ve SSS (-) gruplarının cinsiyet dağılımları arasında istatistiksel olarak anlamlı farklılık gözlenmedi $(p=0,19)$. Ancak erkek bebeklerde SSS (+) olasılığı kız bebeklerden 1,81 $(0,74-4,42)$ kat riskli bulundu.

Çıkarımlar: Birimimizde \% 25,5 olarak belirlediğimiz ölüm oranının doğum öncesi bakım şartlarının düzeltilmesi, steroid kullanımının artması, doğum öncesi bakım eksikliği nedeniyle sık karşılaştığımız erken yenidoğan enfeksiyonların azalması ve nakil koşullarının düzeltilmesi ile daha iyiye gideceği kanısındayız. (Türk Ped Arş 2011; 46: 144-50)

Anahtar sözcükler: Çok düşük doğum ağırlığı, erken doğum, hastalık, ölüm oranı, yenidoğan

\section{Summary}

Aim: The very low birth weight patients in Neonatal İntensive Care Unit (NCIU) have been retrospectively analyzed in order to identify the ratio of morbidity and mortality.

Material and Method: In this study 94 very low birth weight premature babies, which were hospitalized in a two year period in our NICU and compatible with our study criteria were evaluated. The input data (gestational age, birth weight, perinatal risk factors, hospital stay, surfactant therapy, mechanical ventilation strategies, respiratory distress syndrome, intraventricular hemorrhage, periventricular leukomalacia, necrotizing enterocolitis, chronic lung disease and retinopathy of prematurity) of these babies were recorded and analyzed statistically.

Results: In our study the mortality ratio of very low birth weight infants was found to be $25.5 \%$. The most common maternal risk factor was preeclampsia/eclampsia $26.3 \%$ which was compatible with the data of NICHD Neonatal Network Group. The ratios of RDS were found as $100 \%$ in group 1, 93.8\% in group 2, $78.3 \%$ in group 3 and $47.6 \%$ in group 4 and there was no significant difference in gender distribution between RDS (+) and RDS (-) groups ( $p=0.191)$. However probability of RDS in male premature babies was found 1.81 (0.74-4.42) times more risky than female premature babies.

Conclusions: We expect that the mortality ratio of $25.5 \%$ will decrease parallel to the improvement in prenatal care, incareased usage of steroids, neduction of neonatal infections, and improvement of transportation conditions. (Turk Arch Ped 2011; 46: 144-50)

Key words: Morbidity, mortality, newborn, prematurity, very low birth weight

Yazışma Adresi/Address for Correspondence: Dr. Yekta Canbak, S.B. Okmeydanı Eğitim ve Araştırma Hastanesi Çocuk Kliniği, İstanbul, Türkiye

E-mail: yseseogullari@gmail.com Geliş Tarihi/Received: 07.09.2010 Tarihi/Accepted: 20.01.2011

Türk Pediatri Arşivi Dergisi, Galenos Yayınevi tarafindan basılmıștr. / Turkish Archives of Pediatrics, published by Galenos Publishing 


\section{Giriş}

Tüm dünyada yenidoğan ölüm oranı gelişen teknoloji, kullanıma giren yeni ilaçlar ve artan bilgi birikimi nedeniyle belirgin bir şekilde azalmasına rağmen halen önemini korumaktadır (1). Dünyada bebek ölümleri içerisinde yenidoğan ölümleri üçte iki kuralına uymakta, bebek ölümlerinin üçte ikisi ilk ayda, ilk aydaki ölümlerin üçte ikisi ilk haftada, ilk haftadaki ölümlerin de üçte ikisi ilk günde olmaktadır. Yenidoğan bebek ölümlerinin \%30'u perinatal asfiksiye, \%30'u enfeksiyonlara, \%25'i erken doğuma, \%10'u doğuştan malformasyonlara bağlıdır. Düşük doğum ağırlıklı bebekler, yenidoğan ölümlerinde en önemli risk etmenidir $(2,3)$.

Erken doğumların yaklaşık \%25-30'nu oluşturan çok düşük doğum ağırlıklı (ÇDDA; <1500g) erken doğmuş bebekler, daha farklı ve ağır seyreden doğum sonrası sorunları nedeniyle hastalık ve ölüm oranı yüksek bir grubu oluşturmaktadır. Özellikle son 20 yılı aşkın bir süredir perinatal ve yenidoğan bakımındaki ilerlemeler sayesinde ÇDDA bebeklerin sağkalım oranlarında belirgin artış sağlanmıştır. Erken doğum riski olan gebelere doğum öncesi steroid kullanılması, sıkıntılı solunum sendromunun (SSS) önlenmesi ve tedavisinde dışarıdan sürfaktan uygulanması ve mekanik ventilasyon (MV) tedavisindeki yeni uygulamalar bu yenilikler içinde en önemli olanlarıdır (4-9).

Yenidoğan yoğun bakım birimlerinin 1970'li yılların başlangıcında kurulması ile ÇDDA bebeklerin \%50 olan sağkalım oranı \%80'lere çıkmıştır $(4,10,11)$. Ancak tüm bu gelişmelere rağmen gelişmiş ülkelerde 25 haftalıkken doğan bebeklerin yaklaşık yarısı ölmektedir. Gelişmiş ülkelerde bile erken doğmuş çok küçük bebeklerde ölüm oranının yanı sıra hastalık oranı da oldukça yüksektir (12). Bu konularda yapılmış çalışmaların çoğu gelişmiş ülkelerin sonuçlarını yansıtırken, gelişmekte olan ülkelere ait çok az sayıda veri mevcuttur.

Bu çalışmada, iki yıllık dönem içerisinde hastanemiz yenidoğan yoğun bakım biriminde izlenen ÇDDA erken doğmuş bebeklerin, hastalık ve ölüm oranlarının geriye dönük olarak değerlendirilmesi amaçlandı. Bunlara ek olarak, bu verilerle gelişmiş ülkelerde daha önceden bildirilen benzer veriler karşılaştırıldı.

\section{Gereç ve Yöntem}

Hastanemiz Yenidoğan Yoğun Bakım Birimi'nde iki yıl içerisinde yatarak tedavi alan, çok düşük doğum ağırlıklı erken doğmuş bebeklerin dosyaları taranarak hastalık ve ölüm oranları geriye dönük olarak incelendi. Çalışmaya doğum ağırlığı 1500 gr ve altında olup hastanemiz kadın doğum kliniğinde canlı doğan tüm yenidoğanlar ile dış merkezlerde doğup ilk yedi gün içerisinde yenidoğan yoğun bakım birimine kabul edilen toplam 94 yenidoğan alındı. Ölümcül doğumsal anomalileri olan ve dış merkezde izlenip birimimize doğum sonrası yedinci gününden sonra nakil edilen olgular çalışmaya alınmadı.

Gebelik yaşı, tamamlanmış gebelik haftası olarak obstetrik ölçümlerle (son adet tarihi, bilinen obstetrik değişkenler ve ultrasonografi (USG)) ve New Ballard muayenesi ile tayin edildi $(13,14)$. New Ballard muayenesi özellikle anneye ve gebeliğe ait verilerin tam olarak bilinmediği olgularda kullanıldı. Doğumda büyüme geriliği (SGA; doğum ağırlığının gestasyonel yaşa göre 10 . persantilin altında olması) Lubchenco tarafından tanımlanan büyüme eğrileri kaynak alınarak değerlendirildi (15).

Çalışmamıza dahil ettiğimiz hastalar doğum kilosuna göre dört gruba ayrıldı. $<750 \mathrm{~g}$ olanlar grup 1, 750-1000 g arasında olanlar grup 2, 1000-1250 g arasında olanlar grup 3 ve $>1250 \mathrm{~g}$ olan hastalar ise grup 4 olarak tanımlandı. Bu gruplar arasındaki hastalık ve ölüm oranları karşılaştırıldı.

Bu çalışmada istatistiksel analizler NCSS 2007 paket programı ile yapılmıştır. Verilerin değerlendirilmesinde tanımlayıcı istatistiksel yöntemlerin (ortalama, standart sapma) yanı sıra gruplar arası karşılaştırmalarda tek yönlü varyans analizi alt grup karşılaştırmalarında Tukey çoklu karşılaştırma testi, ikili grupların karşılaştırmasında bağımsız $t$ testi, nitel verilerin karşılaştırmalarında ki-kare testi kullanılmıştır. Sonuçlar, anlamlıık $p<0,05$ düzeyinde değerlendirilmiştir.

\section{Bulgular}

Hastanemiz Yenidoğan Yoğun Bakım Birimi'nde iki yıllık dönem içerisinde yatarak tedavi alan erken doğmuş çok düşük doğum ağırlıklı arasında çalışma ölçütlerine uyan 94 olgu çalışmaya alındı. Bu olgular doğum kilolarına göre gruplara ayrıldı (Tablo 1), verileri kaydedilip istatistiksel incelemeleri yapıldı.

Hastalarımızdan 70'i $(\% 74,5)$ hastanemizde doğmuş olup, 24'ü $(\% 25,5)$ dış merkezden tarafımıza sevk edilmiştir. Ölen ve yaşayan hastaların doğum yeri dağılımları karşılaştırılığında her iki grup arasında istatistiksel olarak anlamlı farklılık gözlenmemiştir $(p=0,25)$.

Tablo 1. Hastaların doğum kilolarına göre dağııımı

\begin{tabular}{|c|c|c|c|c|}
\hline & & & $\mathrm{n}$ & $\%$ \\
\hline \multirow[t]{5}{*}{ Doğum kilosu } & Grup 1 & $250-500 \mathrm{gr}$ & 3 & 3,2 \\
\hline & & $501-750 \mathrm{gr}$ & 10 & 10,6 \\
\hline & Grup 2 & $751-1000 \mathrm{gr}$ & 16 & 17 \\
\hline & Grup 3 & $1001-1250 \mathrm{gr}$ & 23 & 24,5 \\
\hline & Grup 4 & $>1250 \mathrm{gr}$ & 42 & 44,7 \\
\hline
\end{tabular}


Çalışmamızdaki 94 olgunun 26'sı çoğul gebelik sonucu dünyaya gelmişti. Ölen ve yaşayan hastaların çoğul gebelik dağılımları karşılaştııılığında her iki grup arasında istatistiksel olarak anlamlı bir farklılık gözlenmemiştir $(p=0,74)$.

Hastalarımızdan 50'si $(\% 53,2)$ erkek, 44'ü $(\% 46,8)$ kız cinsiyete sahipti. Ölen hastalarımızın 16'sı erkek, sekizi, ise kız cinsiyete sahipti. Ölen ve yaşayan hastalar cinsiyet dağılımları açısından karşılaştıııldıklarında her iki grup arasında istatistiksel olarak anlamlı farklılık gözlenmemiştir $(p=0,13)$. Fakat erkek bebeklerde ölüm olasılığı kız bebeklerden 2,12 $(0,8-5,58)$ kat daha riskli bulunmuştur.

Hastalarımızın ortalama doğum kilosu $1145,21 \mathrm{~g}$ olarak bulunmuştur. Grupların ölüm oranları karșılaştıııldığında istatistiksel olarak anlamlı farklılık gözlenmiştir $(p=0,0001)$. Grup 3 ve grup 4'te ölüm oranının diğer gruplara göre düşük olduğu gözlenmiștir (Tablo 2).

Hastaların mekanik ventilasyon süresi ortalamaları açısından karşılaştııılığında gruplar arasında istatistiksel olarak anlamlı farklılık gözlenmiştir $(p=0,001)$. Grup 1'in MV süresi ortalamaları, grup 3'ün MV süresi ortalamasından istatistiksel olarak anlamlı derecede düşük bulunmuş $(p=0,016)$, yine aynı şekilde grup 3'ün MV süresi ortalamaları grup 4'dün MV süresi ortalamasından istatistiksel olarak anlamlı derecede düşük bulunmuştur $(p=0,001)$ (Tablo 2).
Ölen hastaların gebelik haftası ortalamaları, yaşayan hastaların gebelik haftası ortalamalarından istatistiksel olarak anlamlı derecede düşük bulunmuştur $(p=0,0001)$. Ölen hastaların doğum kilosu ortalamaları, yaşayan hastaların doğum kilosu ortalamalarından istatistiksel olarak anlamlı derecede düşük bulunmuştur $(p=0,0001)$. Ölen hastaların yatış süresi ortalamaları, yaşayan hastaların yatış süresi ortalamalarından istatistiksel olarak anlamlı derecede düşük bulunmuştur $(p=0,0001)$. Ölen hastaların MV süresi ortalamaları, yaşayan hastaların MV süresi ortalamalarından istatistiksel olarak anlamlı derecede düşük bulunmuştur $(p=0,002)$ (Tablo 3$)$.

Tüm hastalar arasında intrauterin büyüme geriliği (IUBG) varlığı açısından gruplar arasında istatistiksel olarak anlamlı farklllık gözlenmiştir $(p=0,002)$. Grup 3 ve grup 4'te IUBG oranının düşük olduğu gözlenmiştir. Ölen ve yaşayan hasta gruplarının IUBG dağlımları açısından istatistiksel olarak anlamlı farkllık gözlenmemiştir $(p=0,344)$.

Sıkıntılı solunum sendromu varlığı ve sürfaktan kullanı$\mathrm{mı}$ açısından gruplar arasında istatistiksel olarak anlamlı farkllık gözlenmiştir ( $p=0,0001)$. Grup 4'te SSS (+)'liği oranının düşük olduğu gözlenmiştir. Grup 4'te sürfaktan kullanım oranının düşük olduğu gözlenmiştir (Tablo 2).

Ölen ve yaşayan gruplarının SSS varlığı ve sürfaktan kullanım dağılımları arasında istatistiksel olarak anlamlı

\section{Tablo 2. Hasta gruplarının hastalık ve ölüm oranları açısından karşılaştırıması}

\begin{tabular}{|c|c|c|c|c|c|c|c|c|c|}
\hline \multirow[b]{2}{*}{ SSS (+) } & \multicolumn{2}{|c|}{$<750$ gr n:13 } & \multicolumn{2}{|c|}{$751-1000$ gr n:16 } & \multicolumn{2}{|c|}{$1001-1250$ gr n:23 } & \multicolumn{2}{|c|}{$>1250$ gr n:42 } & \multirow{2}{*}{$\begin{array}{c}\mathbf{p} \\
\chi^{2}: 20,7\end{array}$} \\
\hline & 13 & $\% 100,0$ & 15 & $\% 93,8$ & 18 & $\% 78,3$ & 20 & $\% 47,6$ & \\
\hline SSS (-) & 0 & $\% 0,0$ & 1 & $\% 6,3$ & 5 & $\% 21,7$ & 22 & $\% 52,4$ & $p=0,0001$ \\
\hline Sürfaktan (+) & 13 & $\% 100,0$ & 15 & $\% 93$ & 18 & $\% 78,3$ & 20 & $\% 47,6$ & $\chi 2: 20,7$ \\
\hline Sürfaktan (-) & 0 & $\% 0,0$ & 1 & $\% 6,3$ & 5 & $\% 21,7$ & 22 & $\% 52,4$ & $p=0,0001$ \\
\hline $\mathrm{KAH}(+)$ & 0 & $\% 0,0$ & 2 & $\% 12,5$ & 5 & $\% 21,7$ & 1 & $\% 2,4$ & $\chi^{2: 8,73}$ \\
\hline $\mathrm{KAH}(-)$ & 13 & $\% 100$ & 14 & $\% 87,5$ & 18 & $\% 78,3$ & 41 & $\% 97,6$ & $p=0,033$ \\
\hline ViK (+) & 7 & $\% 53,8$ & 4 & $\% 25,0$ & 1 & $\% 4,3$ & 1 & $\% 2,4$ & $\chi^{2: 25,4}$ \\
\hline $\operatorname{ViK}(-)$ & 6 & $\% 46,2$ & 12 & $\% 75,0$ & 22 & $\% 95,7$ & 41 & $\% 97,6$ & $\mathrm{p}=0,0001$ \\
\hline PVL (+) & 1 & $\% 7,7$ & 1 & $\% 6,3$ & 5 & $\% 21,7$ & 1 & $\% 2,4$ & $\chi^{2: 7,31}$ \\
\hline PVL (-) & 12 & $\% 92,3$ & 15 & $\% 93,8$ & 18 & $\% 78,3$ & 41 & $\% 97,6$ & $p=0,063$ \\
\hline NEK (+) & 0 & $\% 0,0$ & 0 & $\% 0,0$ & 2 & $\% 8,7$ & 0 & $\% 0,0$ & $\chi^{2}: 6,3$ \\
\hline NEK (-) & 13 & $\% 100$ & 16 & $\% 100,0$ & 21 & $\% 91,3$ & 42 & $\% 100,0$ & $p=0,098$ \\
\hline $\mathrm{ROP}(+)$ & 1 & $\% 7,7$ & 2 & $\% 12,5$ & 3 & $\% 13,0$ & 1 & $\% 2,4$ & $\chi^{2: 3,2}$ \\
\hline $\mathrm{ROP}(-)$ & 12 & $\% 92,3$ & 14 & $\% 87,5$ & 20 & $\% 87,0$ & 41 & $\% 97,6$ & $p=0,361$ \\
\hline Yaşayan & 1 & $(\% 7,7)$ & 8 & $(\% 50)$ & 21 & $(\% 91,3)$ & 40 & $(\% 95,2)$ & $\chi^{2}: 48,4$ \\
\hline Ölen & 12 & $(\% 2,3)$ & 8 & $(\% 50)$ & 2 & $(\% 8,7)$ & 2 & $(\% 4,8)$ & $p=0,0001$ \\
\hline Yatış Süresi & \multicolumn{2}{|c|}{$8,31 \pm 24,86$} & \multicolumn{2}{|c|}{$30,81 \pm 33,44$} & \multicolumn{2}{|c|}{$41,74 \pm 24,92$} & \multicolumn{2}{|c|}{$24,9 \pm 9,93$} & $p=0,0001$ \\
\hline MV Süresi & \multicolumn{2}{|c|}{$1,77 \pm 1,48$} & \multicolumn{2}{|c|}{$4,81 \pm 4,94$} & \multicolumn{2}{|c|}{$6,87 \pm 8$} & \multicolumn{2}{|c|}{$1,98 \pm 2,64$} & $p=0,001$ \\
\hline
\end{tabular}

SSS: Sıkıntlı solunum sendromu, KAH: Kronik akciğer hastalı̆̆ı, ViK: Ventrikül içi kanama, PVL: Periventriküler lökomalasi, NEK: Nekrotizan enterokolit,

ROP: Prematüre retinopatisi, MV: Mekanik ventilasyon 
farklllık gözlenmiştir $(p=0,0001)$. Ölen hasta grubunda SSS (+) oranı [24 (\%100)] yaşayan gruptakinden [42 (\%60)] yüksek bulunmuștur. Erkek bebeklerde RDS olasılığı kız bebeklerden 1,81 (0,74-4,42) kat riskli bulunmuştur (Tablo 4).

Sıkıntılı solunum sendromu (+) grubunun gebelik haftası ve doğum kilosu ortalamaları SSS (-) grubundan istatistiksel olarak anlamlı derecede düşük bulunmuştur $(p=0,0001)$. Sıkıntılı solunum sendromu $(+)$ ve SSS (-) gruplarının yatış süresi arasında istatistiksel olarak anlamIı farklılık gözlenmemiştir $(p=0,43)$. Sıkıntılı solunum sendromu (+) grubunun MV süresi ortalamaları SSS (-) grubundan istatistiksel olarak anlamlı derecede yüksek bulunmuştur $(p=0,0001)$ (Tablo 5). Hastalarımızın sadece 17 'sinde $(\% 18,1)$ doğum öncesi steroid uygulanmıştı.

Hasta grupları arasında prematüre retinopatisi (ROP) dağılımları açısından istatistiksel olarak anlamlı farklııık gözlenmemiştir $(p=0,36)$. Ölen ve ölmeyen hastalar ROP dağılımları açısından incelendiğinde her iki grup arasında istatistiksel olarak anlamlı farklılık gözlenmemiştir $(p=0,11)$ (Tablo 2).

Nekrotizan enterokolit (NEK) varlığı açısından gruplar arasında istatistiksel olarak anlamlı farklılık gözlenmemiştir $(p=0,10)$. Ölen ve yaşayan hastalar arasında NEK varlığı açısından karşılaştırıldığında istatistiksel olarak anlamlı farklılık gözlenmemiştir $(p=0,42)$ (Tablo 2).

Ventrikül içi kanama (VIK) varlığı açısından gruplar arasında istatistiksel olarak anlamlı farklılık gözlenmiş$\operatorname{tir}(p=0,0001)$. Grup 3 ve grup 4'te ViK varlığı oranının düşük olduğu gözlenmiştir. Ölen ve yaşayan hastaların ViK pozitifliği açısından karşılaştırılığında istatistiksel olarak farklılık gözlenmiştir $(p=0,0001)$. Kaybedilen bebeklerde ViK (+) [13 $(\% 54,2)]$ oranı yaşayan grubundan [0 $(\% 0,0)]$ yüksek bulunmuştur (Tablo 2).

\begin{tabular}{|l|c|c|c|c|}
\hline \multicolumn{5}{|c|}{ Tablo 3. Ölen ve yaşayan hastaların karşılaştırılması } \\
\hline & Yaşıyor n:70 & Ölen n:24 & T & p \\
\hline Gebelik haftası & $30,61 \pm 2,05$ & $26 \pm 2,06$ & 9,52 & 0,0001 \\
Doğum kilosu & $1263,57 \pm 192,51$ & $800 \pm 268,73$ & 7,79 & 0,0001 \\
Yatış süresi & $36,64 \pm 20,84$ & $1,75 \pm 1,75$ & 13,86 & 0,0001 \\
MV süresi & $4,27 \pm 5,81$ & $1,75 \pm 1,75$ & 3,23 & 0,002 \\
\hline
\end{tabular}

Tablo 4. Respiratuar distres sendromu varlığı ve surfaktan kullanımına göre ölüm oranları

\begin{tabular}{|l|c|c|c|c|c|}
\hline & \multicolumn{2}{|c|}{ Yaşıor } & \multicolumn{2}{c|}{ Exitus } & \\
\hline SSS (+) & 42 & $\% 60,0$ & 24 & $\% 100,0$ & $\chi^{2: 13,6}$ \\
SSS (-) & 28 & $\% 40,0$ & 0 & $\% 0,0$ & $\mathrm{p}=0,0001$ \\
Var & 42 & $\% 60,0$ & 24 & $\% 100,0$ & $\chi^{2: 13,6}$ \\
Yok & 28 & $\% 40,0$ & 0 & $\% 0,0$ & $\mathrm{p}=0,0001$ \\
\hline
\end{tabular}

SSS: Sıkıntılı solunum sendromu
Kronik akciğer hastalığı (KAH) varlığı dağılımları açısından gruplar arasında istatistiksel olarak anlamlı farklılık gözlenmiştir $(p=0,03)$. Grup 4'te KAH varlığı oranının düşük olduğu gözlenirken, ölen ve yaşayan hastalar arasında $\mathrm{KAH}$ varlığı açısından istatistiksel olarak anlamlı farklılık gözlenmemiştir ( $p=0,08)$ (Tablo 2).

Gruplar arasında periventriküler lökomalasi (PVL) varlığı dağılımları açısından istatistiksel olarak anlamlı farklılık gözlenmemiştir $(p=0,06)$. Ölen ve yaşayan hastalar arasında PVL varlığı açısından istatistiksel olarak anlamlı farkllık gözlenmemiştir $(p=0,08)$ (Tablo 2).

Ölüm oranları açısından gruplar arasında istatistiksel olarak anlamlı farklılık gözlenmiştir ( $p=0,0001)$. Grup 3 ve grup 4'te ölüm oranının düşük olduğu gözlenmiştir (Tablo 2).

Tüm hastaların hastalık ve ölüm oranları Tablo 6'de görülmektedir. Hasta grupları arasındaki hastalık oranları ise Şekil 1'de görülmektedir. Hastalıksız sağ kalım oranları incelendiğinde gruplar arasında istatistiksel olarak anlamlı farklılık gözlenmiștir $(p=0,0001)$. Grup 4'te hastalıksız sağkalım oranının yüksek olduğu gözlenmiştir (Tablo 7).

\section{Tartışma}

Erken doğum; perinatal, yenidoğan ve doğum sonrası dönemlerde hastalık ve ölümün önemli bir nedeni olarak kalmaya devam etmektedir. Erken doğumların yaklaşık \%2530'unu oluşturan çok düşük doğum ağırlıklı bebekler, daha farklı ve ağır seyreden doğum sonrası sorunları nedeniyle hastalık ve ölüm oranı yüksek bir grubu oluşturmaktadır. Özellikle son 20 yıldan fazla bir süredir perinatal ve yenidoğan bakımdaki ilerlemeler sayesinde çok düşük doğum ağırlıklı bebeklerin sağkalım oranlarında belirgin artış sağlanmıştır. Erken doğum riski olan gebelere doğum öncesi steroid kullanılması, SSS'nin önlenmesi ve tedavisinde sürfaktan uygulanılması, mekanik ventilatör tedavisindeki yeni uygulamalar bu yenilikler içinde en önemli olanlarıdır (4-9).

Çalışmamızda çok düşük doğum ağırıklı bebeklerde ölüm oranımız \%25,5 olarak bulunmuştur. Az gelişmiş ve gelişmekte olan bazı ülkelerden bildirilen çalışmalara bakıldığında yenidoğan yoğun bakımda izlenen çok düşük doğum ağırlıklı bebeklerde ölüm oranı Singapur'da \%17, Malezyada \%34, Hindistanda \%30 saptanmıştır (16).

Tablo 5. Respiratuar distres sendromu gelişen ve gelişmeyen hastaların karşılaştırılması

\begin{tabular}{|l|c|c|c|c|}
\hline & SSS (+) n:66 & SSS (-) n:28 & t & p \\
\hline Gestasyonel hafta & $28,39 \pm 2,63$ & $31,89 \pm 1,69$ & $-6,48$ & 0,0001 \\
Doğum kilosu & $1063,03 \pm 305,92$ & $1338,93 \pm 133,20$ & $-6,09$ & 0,0001 \\
Yatış süresi & $28,64 \pm 27,53$ & $25,61 \pm 9,31$ & 0,79 & 0,430 \\
MV süresi & $5,11 \pm 5,57$ & $0,14 \pm 0,53$ & 4,69 & 0,0001 \\
\hline
\end{tabular}

SSS: Sıkıntilı solunum sendromu 
Erken doğmuş bebeklerin yaşama şansını belirleyen en önemli etkenler doğum ağırlığı ve doğum haftasıdır (12). Çalıșmamızda doğum ağırlığı ortalamaları açısından ölen ve yaşayan hastalar arasındaki fark istatistiksel olarak anlamlı bulundu $(p<0,05)($ Tablo 3). Doğum ağırlığı arttıkça ölüm oranı azalmakta olup bu fark istatistiksel açıdan anlamlı saptandı $(\mathrm{p}<0,05)$. Grup 3 ve Grup 4'te ölüm oranının düşük olduğu gözlendi (Tablo 2).

Amerikan Ulusal Çocuk ve İnsan Gelişimi Yenidoğan Çalışma Grubu (National Institute of Child Health and Human Developmental(NICHD)-Neonatal Network) verilerine göre 1988'de 501-750 g arasındaki yenidoğanlarda \%66 olan ölüm oranının 1996'da \%48'e düştüğü saptanmıştır ve 1988 ile 1996 yıllarında, doğum ağırlı̆ı̆ 751-1000 $\mathrm{g}$ arasında olan bebeklerin ölüm oranları \%34'den \%14'e, 1001-1250 g arasında olanlarda \%13'den \%6'ya, $1251-1500 \mathrm{~g}$ arasında olanlarda ise \%7'den \%3,5'e düşmüştür (17). Atasay ve ark'larının 2003 yılında yaptıkları çalışmada, ÇDDA erken doğmuş bebeklerin ölüm oranı \%16,5 ve vücut kilolarına göre ölüm oranları $750 \mathrm{~g}$ ve altı, 751-1000 g, 1001-1250 g, 1251-1500 g arasında olanlar için sırasıyla \%80,7, \%20,1, \%8,9, \%5,3 olarak bildirilmiştir (18). Bu verilerle karşılaştıııldığında 1000 g'ın altındaki bebekler için ölüm oranlarımız yüksek bulunurken, 1000 g'ın üzerindeki ölüm oranlarımız düşük saptanmıştır.

Tablo 6. Tüm hastaların hastalık ve ölüm oranları

\begin{tabular}{|c|c|c|c|c|}
\hline & & $\mathbf{n}$ & $\begin{array}{l}\text { Hastalık } \\
\text { oran } \%\end{array}$ & $\begin{array}{c}\text { Ölüm } \\
\text { oran n (\%) }\end{array}$ \\
\hline IUBG & $\begin{array}{l}\text { IUBG (+) } \\
\text { IUBG(-) }\end{array}$ & $\begin{array}{l}14 \\
80\end{array}$ & $\begin{array}{l}\% 14,9 \\
\% 85,1\end{array}$ & $5(\% 35,7)$ \\
\hline SSS & $\begin{array}{l}\text { SSS (+) } \\
\text { SSS (-) }\end{array}$ & $\begin{array}{l}66 \\
28\end{array}$ & $\begin{array}{l}\% 70,2 \\
\% 29,8\end{array}$ & $24(\% 36,4)$ \\
\hline Survanta & $\begin{array}{l}\text { Var } \\
\text { Yok }\end{array}$ & $\begin{array}{l}66 \\
28\end{array}$ & $\begin{array}{l}\% 70,2 \\
\% 29,8\end{array}$ & $24(\% 36,4)$ \\
\hline ROP & $\begin{array}{l}\text { Var } \\
\text { Yok }\end{array}$ & $\begin{array}{c}7 \\
87\end{array}$ & $\begin{array}{c}\% 7,4 \\
\% 92,6\end{array}$ & $0(\% 0)$ \\
\hline NEK & $\begin{array}{l}\text { Var } \\
\text { Yok }\end{array}$ & $\begin{array}{c}2 \\
92\end{array}$ & $\begin{array}{c}\% 2,1 \\
\% 97,9\end{array}$ & $1(\% 50)$ \\
\hline ViK & $\begin{array}{l}\text { Var } \\
\text { Yok }\end{array}$ & $\begin{array}{l}13 \\
81\end{array}$ & $\begin{array}{l}\% 13,8 \\
\% 86,2\end{array}$ & $13(\% 100)$ \\
\hline $\mathrm{KAH}$ & $\begin{array}{l}\text { Var } \\
\text { Yok }\end{array}$ & $\begin{array}{c}8 \\
86\end{array}$ & $\begin{array}{c}\% 8,5 \\
\% 91,5\end{array}$ & $0(\% 0)$ \\
\hline PVL & $\begin{array}{l}\text { Var } \\
\text { Yok }\end{array}$ & $\begin{array}{c}8 \\
86\end{array}$ & $\begin{array}{c}\% 8,5 \\
\% 91,5\end{array}$ & $0(\% 0)$ \\
\hline SONUÇ & $\begin{array}{l}\text { Yaşıyor } \\
\text { Exitus }\end{array}$ & $\begin{array}{l}70 \\
24\end{array}$ & $\begin{array}{l}\% 74,5 \\
\% 25,5\end{array}$ & \\
\hline
\end{tabular}

Not: Olguların bazılarında birden fazla hastalık mevcuttur.

IUBG: İntrauterin büyüme geriliği, SSS: Sıkıntılı solunum sendromu, KAH: Kronik akciğer hastalığı, VIK: Ventrikül içi kanama, PVL: Periventriküler lökomalasi, NEK: Nekrotizan enterokolit, ROP: Prematüre retinopatisi
Ölen olgularda ortalama gebelik yaşı 26 hafta bulunurken yaşayanlarda 30,6 hafta bulundu. Gestasyon haftalarına göre ölüm oranlarımız, 22-24, 25-26, 27-28, 29-30, 31-32 ve 33-34 gestasyonel haftalara göre sırasıyla \%100, $\% 90, \% 30,7, \% 10, \% 3,0$ ve \%0 bulunmuştur. Bu oranlar ülkemizde Türk Neonatoloji Derneği'nin 31 yenidoğan yoğun bakım birimi verilerinden oluşan çok merkezli araştırmasında gestasyon yaşlarına göre 2007 yılı ölüm oranları ile karşılaştııılığında $22-24,25-26$ ve 27-28 gestasyonel haftalı gruplarda yüksek, 29-30 ve 31-32 gestasyonel haftalı gruplarda daha düşük saptanmıştır (19).

Gestasyon haftası ve doğum ağırlığı hastalık ve ölüm oranının en önemli belirleyicileri kabul edilse ve pek çok çalışmada ölüm oranı üzerine etkileri ilişkili bulunsa da gebelik haftası yenidoğanın matüritesiyle ilgili daha doğru bilgi vereceğinden daha anlamlı kabul edilmektedir. Ancak gebelik haftası doğum öncesi iyi izlem ve erken ultrason yapılmadıysa gerçeği yansıtmayabilir. Bu nedenle doğum kilosunun kolaylıkla belirlenebilmesi ve nesnel olması nedeniyle kullanımının daha pratik olduğu düşünülmektedir (20).

Çalışmamızda erkek olgularda \%32 olan ölüm oranı kIz olgularda \%18,2 olarak bulundu. Bu fark istatistiksel açıdan anlamlı değildi. Bu açıdan sonuçlarımız literatür verileriyle uyumlu olmayıp, yapılan pek çok çalışmada erken doğmuş erkek bebeklerde ölüm riskinin arttı̆̆ı gösterilmiştir (21). Çalışmamızda erkek bebeklerde ölüm olasılığı kız bebeklerden $2,12(0,8-5,58)$ kat riskli bulunmuştur. NICHD Neonatal Research Network grubunun

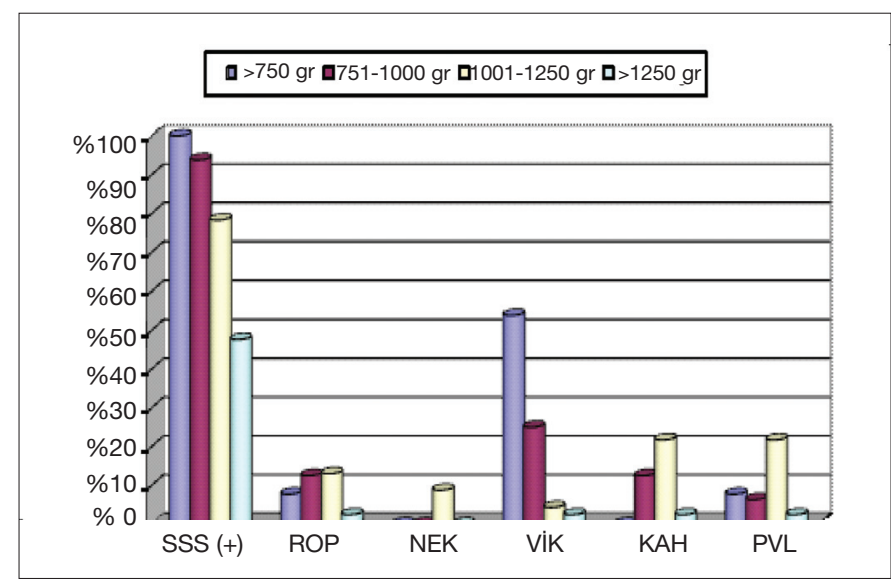

Şekil 1. Hasta grupları arasında hastalık oranları

SSS: Sıkıntılı solunum sendromu, KAH: Kronik akciğer hastalığı, ViK: Ventrikül içi kanama, PVL: Periventriküler lökomalasi, NEK: Nekrotizan enterokolit, ROP: Prematüre retinopatisi

Tablo 7. Hasta grupları arasında hatalıksız sağkalım oranlarımız

$<750$ gr $751-1000$ gr $1001-1250 \mathrm{gr}>1250 \mathrm{gr}$

Hastalıksız $\quad 5 \% 38,510 \% 62,5 \quad 13 \% 56,5 \quad 39 \% 92,9 p=0,0001$

sağkalım (+) 
raporlarında da aynı doğum ağırlığı ve gebelik haftasına göre kıyaslandığında erkeklerdeki ölüm oranının kızlardan daha yüksek olduğu bildirilmiştir (17).

Erken doğum riski olan gebelere doğum öncesi uygulanan steroid tedavisinin SSS riskini, kafa içine kanamayı ve ölüm oranını azalttığı bilinmektedir. NICHD Neonatal Research Network verilerine göre doğum öncesi steroid kullanımı 1988'de \%16 iken 1996'da \%71'e yükselmiştir. Vermont-Oxford Network çalıșmalarında bu oran 1991'de \%24 iken 1999'da \%72 olmuştur. Bizim çalışmamızda ise erken doğum yapan annelerin yalnızca \%18,1'ine doğum öncesi steroid uygulanabilmiştir. Bu orandaki düşüklüğün nedeni olarak, doğumu hastanemizde gerçekleşen gebelerin sadece \%66'sının düzenli takipli olmasından kaynaklandığını düşünmekteyiz.

En sık karşılaşılan anneye ait risk etkenleri preeklampsi/eklampsi $(\% 26,3)$ olup sonuçlarımız NICHD Neonatal Network grubunun verileri ile uyumluydu (17). Sıkıntılı solunum sendromu sıklığı, ağırlığı gebelik haftası ve doğum ağırlığı azaldıkça artar (22). Sıkıntılı solunum sıklığı 26-28. gebelik haftasındaki bebeklerin \%50-85'inde görülürken, 30-31. haftalarda sıklık \%40'a, 34. haftada \%10-15'e ve 36 haftada \%1'e iner (23).

Çalışmamızda 500-750 g arasında SSS oranı \%100, grup 2'de \%93,8, grup 3'te \%78,3 ve grup 4'te \%47,6 olup Hack ve ark'larının yaptığı çalışma sonuçlarıyla uyumlu bulunmuştur. Sıkıntlı solunum sendromu (+) ve SSS (-) gruplarının cinsiyet dağılımları arasında istatistiksel olarak anlamlı farklılık gözlenmemiştir $(p=0,191)$. Ancak erkek bebeklerde SSS (+) olasilığı kız bebeklerden 1,81 $(0,74-4,42)$ kat riskli bulunmuştur. Literatürde erkek bebeklerde SSS sıklığının kızlara göre yüksek olduğu belirtilmiştir (22).

Çok düşük doğum ağılıklı yenidoğanlarda azalan ölüm oranıyla ilişkili olarak, ağır ViK, NEK, PVL ve KAH'ı içeren ciddi hastalıklar giderek artan oranlarda karşımıza çıkmaktadır. Amerikan Ulusal Çocuk ve İnsan Gelişimi Yenidoğan Çalışma Grubu merkezlerinin altı yıllık izleminde ÇDDA bebeklerde ölüm oranları belirgin olarak azalırken hastalık oranlarındaki artış dikkati çekmektedir. 1991 yılında \%27 olan ciddi hastalık oranı kronik akciğer hastalığındaki artışa (1991'de \%9, 1996'da \%23) bağlı olarak 1996 yılında \%30'a yükselmiştir (14). Kafa içine ağır kanama sıklığı 1991 yılında \%8,4 iken 1996'da \%11, NEK sıklığı ise 1991 yllında \%4,5 iken 1996'da \%5 olarak bildirilmiştir (17).

Amerika Birleşik Devletleri'nde her yıl 7500 yeni KAH tanısı konmakta ve bu bebeklerin \%10'u ilk yıl içinde komplikasyonlarla kaybedilmektedir (24). Sürfaktanın uygulamaya girmesi ve yoğun bakım hizmet niteliğinin artması bir taraftan $\mathrm{KAH}$ riskini azaltırken, diğer taraftan daha riskli bebeklerin yaşam oranlarını arttırmış ve göreceli olarak KAH sıklığı da artmıştır (24). NICHD verilerine göre sağ kalım oranları artmakla birlikte $\mathrm{KAH}$ sıklığında azalma görülmemiştir (\%23) (17). Ülkemizdeki merkezlerden KAH sıklıkları \%2,3-\%10,5 arasında bildirilmiştir (21). Çalışmamızda KAH oranı \%8,5 olup ülkemizdeki verilerle uyumludur. Grup 3'te KAH görülme sıklığının grup 2'e göre daha yüksek olması grup 2'deki ölüm oranının belirgin olarak yüksek olmasına bağlanmıştır.

Son 20-30 yılda periventriküler (PV)-ViK ve PVL sıklığı giderek düşmekle birlikte 1500 g'nin altındaki bebeklerde hala \%5,6-11,6 ağır PV-ViK bildirilmektedir. Bu oran doğum ağırlığı 500-750 g arasında olan bebeklerde \%26 ve 750-1000 g arasında olan bebeklerde \%12'dir. Aynı çalışmada doğum ağırlığı $1500 \mathrm{~g}$ altında olan bebeklerde \%5 PVL (500-1000 g arasında \%7) bildirilmiştir (25). Ülkemizde de Köksal ve ark'ları (26) 2002 yılında 1500 g'ın altında doğan 120 bebekte PV-ViK oranını \%15 bildirmişlerdir. Çalışmamızda grupların ViK varlığı dağılımları arasında istatistiksel olarak anlamlı farklılık gözlenmiştir ( $p=0,0001)$. Grup 3 ve grup 4'te ViK varlığı oranının düşük olduğu gözlenmiştir. Bu oran NICHD verilerine göre yüksek olup Köksal ve ark'larının 2002 yılında yaptığı çalışma sonuçları ile uyumlu bulunmuştur.

Nekrotizan enterokolit sıklığı, azalan doğum ağırığı ve azalan gestasyon yaşı ile orantılı olarak artmaktadır. Wilson ve ark'ları (27) 148 NEK'li hastayı değerlendirmişler ve en yüksek oranların $1000 \mathrm{~g}$ altındaki bebeklerde $\% 42$ olduğunu görmüşlerdir. Doğum ağırlı̆ı 1000-1500 g arasındaki bebeklerde \%39,0, 1501-2000 arasındaki grupta \%3,8, 2500 g'ın üstündeki bebeklerde ise $\% 0,11$ oranında NEK saptamışlardır. Evre III-IV Nekrotizan enterokolit yalnızca 2 $(\% 2,1)$ olgumuzda görüldü ve bu oran NICHD Neonatal Research Network'ün 1996 yllındaki oranından düşüktü (17). Nekrotizan enterokolit varlığı açısından gruplar arasında istatistiksel olarak anlamlı farkllık gözlenmemiştir $(p=0,010)$. Bu durum olgu sayısının az olmasına bağlanmıştır.

Son zamanlarda yapılan hem geriye dönük hem de ileriye dönük çalışmalarda, hastaneden hastaneye ve toplumdan topluma değişmek üzere, ROP sıklık ve şiddetinde çok geniş bir dağılım aralı̆̆ında veriler bildirilmektedir (28-42). Ileriye yönelik, farklı toplumlarda yapılmış ve çok merkezli çalışma sayısı azdır. Çalışmamızda Evre III ve üstündeki ROP oranı \%7,4 bulunmuştur ve 1250 g'ın altındaki hastalarda bu oran \%11,5 olup her iki oran da literatür verileri ile uyumlu bulunmuştur. Hasta grupları arasında ROP dağılımları açısından istatistiksel olarak anlamlı farklılık gözlenmemiştir $(p=0,361)$. Bu durum olgu sayısının az olmasına bağlanmıştır.

Çalışmamızda ciddi hastalık hali olmadan sağ kalım $\% 71,3$ olup grupların hastalıksız sağ kalım varlığı dağılımları arasında istatistiksel olarak anlamlı farklılık gözlenmiştir ( $p=0,0001)$. Grup 4'te hastalıksız sağ kalım oranının yüksek olduğu gözlenmiştir.

Birimimizde \%25,5 olarak belirlediğimiz ölüm oranının doğum öncesi bakım şartlarının düzeltilmesi, steroid kullanımının artması, doğum öncesi bakım eksikliği nedeniyle sık karşılaştığımız erken yenidoğan enfeksiyonların azalması ve nakil koşullarının düzeltilmesi ile daha iyiye gideceği kanısındayız.

Çıkar çatışması: Bildirilmedi. 


\section{Kaynaklar}

1. Lawn JE, Cousens, Bhutta ZA, et al. Why are 4 million newborn babies dying each year? Lancet 2004; 364: 399-401.

2. Dogramaci İ. yenidoğan ölümleri. Yurdakök M, Erdem G (edt) Türk Neonatoloji Derneği. Neonatoloji, 2003; 3-5.

3. Horbar JD, Badger GJ, Carpenter JH, et al. Trends in mortality and morbidity for very low birth weight infants, 19911999. Pediatrics 2002; 110: 143-51.

4. Horbar JD, Wright EC, Onstad L. Decreasing mortality associated with the introduction of surfactant therapy: an observational study of neonates weighing 601-1300 grams at birth. Pediatrics 1993; 92: 191-6.

5. Jobe AH. Pulmonary surfactant therapy. N Engl J Med 1993; 328: 861-8

6. Horbar JD, Wright LL, Soll RF, et al. A multicenter randomized trial comparing two surfactants for the treatment of neonatal respiratory distress syndrome. National Institute of Child Health and Human Development Neonatal Research Network. J Pediatr 1993; 123: 757-66.

7. NIH Consensus Development Panel on the Effect of Corticosteroids for Fetal Maturation on Perinatal Outcomes. Effect of corticosteroids for fetal maturation on perinatal outcomes. JAMA 1995; 273: 413-8.

8. Greenough A, Milner AD, Dimitriou G. Prendergast M. Synchronized mechanical ventilation for respiratory support in newborn infants. Cochrane Database Syst Rev 2001; 1: CD000456.

9. Cools F, Henderson-Smart DJ, Offringa M, Askie LM. Elective high frequency oscillatory ventilation versus conventional ventilation for acute pulmonary dysfunction in preterm infants. Cochrane Database Syst Rev 2009; 8: CD000104.

10. Stewart AL, Reynolds EO, Lipscomb AP. Outcome for infants of very low birthweight: survey of world literature. Lancet 1981; 1: $1038-40$.

11. Lagercrantz H, Katz-Salamon M, Forssberg H. The Stockholm neonatal project: Neonatal mortality and morbidity at the Children's Centre, Karolinska Hospital. Acta Paediatr Suppl 1997; 419: 11-5.

12. Stoll BJ, Kliegman RM. The Fetus and the Neonatal Infant. In: Behrman RE, Kliegman RM, Jenson HB (eds). Nelson Textbook of Pediatrics. 17th ed. Philadelphia: W.B. Saunders Company 2003; 519-640.

13. Ballard JL, Novak KK, Driver M. A simplified score for assesment of fetal malnutrition of newly born infants. J Pediatr 1979; 95: 769-74.

14. Ballard JL, Khoury JC, Wedig K, Wang L, Eilers-Walsman BL, Lipp R. New Ballard Score, expanded to include extremely premature infants. J Pediatr 1991; 119: 417-23.

15. Lubchenco LO, Hansman C, Dressler M, Boyd H. Intrauterin growth as estimated from liveborn birtweight data at 24-42 weeks of gestation. Pediatrics 1963; 32: 793-800.

16. A national study of risk factors associated with mortality in very low birthweight infants in the Malaysian neonatal intensive care units. Malaysian Very Low Birth Weight Study Group. J Peaditr Child Health 1997; 33: 18-25.

17. Hack M, Horbar JD, Malloy MH, Tyson JE, Wright E, Wright L. Very low birth weight outcomes of the National Institute of Child Health and Human Developmental Neonatal Network. Pediatrics 1991; 87: 587-97.

18. Atasay B, Günlemez A, Ünal S, Arsan S. Outcomes of very low birth weight infants in a newborn tertiary center in Turkey, 1997-2000. Turk J Pediatr 2003; 45: 283-9.

19. Türkiye'de yenidoğan bakım ünitelerinde mortalite oranları 2007. Türk Neonatoloji Derneği Bülteni 2008; 17: 15-9.

20. Türkiye'de yenidoğan bakım ünitelerinde mortalite oranları 2004. Türk Neonatoloji Derneği Bülteni 2004; 10: 10-4.

21. Duman N, Kumral A, Gulcan H, Ozkan H. Outcome of very-low-birth-weight infants in a developing country: a prospective study from the western region of Turkey. $J$ Matern Fetal Neonatal Med 2003; 13: 54-8.
22. Greenough A, Roberton NRC. Respiratory Distres Syndrome. In: Neonatal Respiratory Disorders. Greenough A, Milner AD, Roberton NRC (eds). 1st Ed. London: Arnold, The Hodder Headline Group, 1996; 238-79.

23. Rodriguez RJ, Martin RJ, Fanaroff AA. Respiratory Distres Syndrome and its Management. In: Fanaroff AA, Martin RJ (eds). Neonatal-Perinatal Medicine. 7th ed. St. Louis: Mosby 2002; 1001-11.

24. Davis MJ, Rosenfeld WN. Chronic Lung Disease. In: Avery GB, Fletcher AM, Macdonald MG (eds). Neonatology Pathophysiology and management of the Newborn. 5th ed. Philadelphia: Lippincott Williams and Wilkıns, 1999; 509-31.

25. Lemons JA, Bauer CR, Oh W, et al. Very low birth weight outcomes of the national instuitude of child health and human development, neonatal research network, January 1995 through December 1996. Pediatrics 2001; 107:1.

26. Köksal N, Baytan B, Bayram Y, Nacarküçük E. Risk factors for intraventricular hemorrage in very low birth weight infants. Indian J Pediatr 2002; 69: 561-4.

27. Wilson R, Kanto WP Jr, McCarthy BJ, et al. Epidemiologic characteristics of necrotizing enterocolitis: a population-based study. Am J Epidemiol 1981; 114: 880-7.

28. Lee SK, McMillan DD, Ohlsson A, et al. Variations in practice and outcomes in the Canadian NICU Network: 996-1997. Pediatrics 2000; 106: 1070-9.

29. Palmer EA, Flynn JT, Hardy RJ, et al. Incidence and early course of retinopathy of prematurity. The Cryotherapy for Retinopathy of Prematurity Cooperative Group. Ophthalmology 1991; 98: 1628-40.

30. Brown MS, Baron AE, France EK, Hamman RF. Association between higher cumulative doses of recombinant erythropoietin and risk for retinopathy of prematurity. J AAPOS 2006; 10: 143-9.

31. Blair BM, O'halloran HS, Pauly TH, Stevens JL. Decreased incidence of retinopathy of prematurity,1995-1997. J AAPOS 2001; 5: 118-22.

32. Mathew MR, Fern Al, Hill R. Retinopathy of prematurity: are we screening too many babies? Eye 2002; 16: 538-42.

33. Shah VA, Yeo CL, Ling YL, Ho LY. Incidence, risk factors of retinopathy of prematurity among very low irth weight infants in Singapore. Ann Acad Med Singapore 2005; 34: 169-78.

34. Phan MH, Nguyen PN, Reynolds JD. Incidence and severity of retinopathy of prematurity in Vietnam a developing middle-income country. J Pediatr Ophthalmol Strabismus 2003; 40: 208-12.

35. Parsson E, Carle-Petrelius B, Cernerud G, Ots L, Wallin A, Holmstrom G. Incidence of ROP in two consecutive Swedish population based studies. Br J Ophthalmol 2002; 86: 1122-6.

36. Mayet I, Cockinos C. Retinopathy of prematurity in South Africans at a tertiary hospital: a prospective study. Eye (Lond) 2006; 20: 29-31.

37. Delport SD, Swanepoel JC, Odendaal PJ, Roux P. Incidence of retinopathy of prematurity in very-lowbirth-weight infants born at Kalafong Hospital, Pretoria. S Afr Med J 2002; 92: 986-90.

38. Yanovitch TL, Siatkowski RM, McCaffree M, CorffKE. Retinopathy of prematurity in infants with birth weight>or=1250 grams-incidence, severity, and screening guideline cost-analysis. J AAPOS 2006; 10: 128-34.

39. Mutlu FM, Altınsoy Hi, Mumcuoğlu T, et al. Frequency and risk factor analysis for retinopathy of prematurity: a multivariate statistical analysis. J Pediatr Ophthalmol Strabismus 2008; 45 (8).

40. United Nations Development Programme (UNDP). Human Development Report, 2004. http://hdr.undp.org/reports (last accessed November 22, 2006).

41. Early Treatment for Retinopathy of Prematurity Cooperative Group. Revised indications for the treatment of retinopathy of prematurity: results of the early treatment for retinopathy of prematurity randomized trial. Arch Ophthalmol 2003; 121: 1684-96.

42. Good WV, Hardy RJ, Dobson V, et al. The incidence and course of retinopathy of prematurity: findings from the early treatment for retinopathy of prematurity study. Pediatrics 2005; 116: 15-23. 